\title{
Sensitivity analysis for concentrating solar power technologies
}

\author{
B. Webby ${ }^{a}$ \\ ${ }^{a}$ Barbara Hardy Institute, University of South Australia, 111 Nicolson Avenue, Whyalla Norrie, South \\ Australia, 5608 \\ Email: brian.webby@unisa.edu.au
}

\begin{abstract}
There are potential reductions in greenhouse gas emissions to the atmosphere through the generation of elec-tricity from renewable energy sources. Wind power and photovoltaic panels are welldeveloped technologies now, and have achieved significant reductions in costs as their industries matured. Renewable energy can also be generated through large-scale solar thermal plants, whereby a field of solar collectors concentrate the sun's energy to heat a fluid that is then passed to a conventional steam generator. This technology is in a develop-mental stage, with the benefits from learning from experience with pilot plants, from mass production, and from innovation not yet obtained.

The Australian Solar Thermal Research Initiative (ASTRI) is a federal government program to investigate technologies that will reduce the cost of electricity produced by concentrating solar power (CSP) plants. One aspect of the program is to develop a methodology to create a baseline economic model for the costs of typical CSP plants, and use this to assess the potential for cost reductions of research activities. Part of the methodology is the System Advisor Model (SAM) developed by an ASTRI partner, the U.S.'s National Renewable Energy Laboratory. SAM is an industry standard model for comparing the performance of solar thermal or photovoltaic plants. The analysis reported here, and the framework for the economic model for the ASTRI program, uses SAM and solar data from Longreach, Queensland.

This paper reports on basic outcomes from the SAM model for two solar tower systems, one with storage and one without, comparing results mainly in terms of the levelised cost of electricity achieved by the plants. Standard settings for SAM are used, some of which are later systematically varied during sensitivity analysis on model inputs.
\end{abstract}

Keywords: Concentrating solar power, Sensitivity analysis, Levelised cost of electricity 


\section{INTRODUCTION}

The Australian Solar Thermal Research Initiative (ASTRI) aims to investigate technologies and applications that will reduce the cost of electricity produced by concentrating solar power (CSP) plants. Under the program, research would be prioritised in areas where significant cost reductions appear possible, and an initial focus is to develop a standard methodology to compare costs (or cost savings) for alternate research proposals. A key component of the methodology is the System Advisor Model (SAM) developed by an ASTRI partner, the U.S.'s National Renewable Energy Laboratory. SAM is an industry standard model for comparing the performance of solar thermal or photovoltaic plants. It combines a simulation of the performance of the various components of a solar power system (collector field, receivers, power block, stored energy) driven by hourly site-specific solar radiation, with a cost and finance model to calculate (among other parameters) energy output and energy cost.

The analysis reported here uses SAM and solar data from Longreach, QLD, and a generic model of a CSP generator. Standard settings for SAM are used, some of which are later systematically varied during sensitivity analysis on model inputs in an exploration of areas where research might achieve the most significant reductions in electricity cost. Longreach is a prospective site for a solar power station and is becoming a benchmark for such sites in Australia. Global solar radiation data for the site are derived from satellite gridded data and an hourly direct normal radiation (dni) data set was developed and verified by the Bureau of Meteorology. A typical meteorological year is available for the site and is a required input to SAM; the annual representative dni is estimated to total $2564 \mathrm{kWh} / \mathrm{m}^{2}$. Longreach data have been used in studies by Hinckley et.al (2012) and Lovegrove $(2012$, 2013). Baseline lcoe values have been found for the site for various solar power technologies in these studies.

Concentrating solar power plants use a field of mirrors to focus direct beam sunlight onto a receiver. A fluid in the receiver (usually oil, water or molten salt) is heated to several hundred degrees Centigrade and is passed to a heat engine (eg a steam turbine) where the heat is used to generate electricity, or the fluid is sent to storage tanks for later use in the heat engine. While parabolic trough designs are more than $90 \%$ of the current industrial-sized CSP plants, dish and solar tower systems are a research and prototype interest because of their capacity to generate higher temperatures and benefit from efficiencies in the steam cycle. Solar towers have a receiver mounted in a central tower receiving reflected radiation from a field of heliostats which have mirrored surfaces and track the sun on two axes. A heat transfer fluid (steam or molten salts in current systems) is passed through the receiver and delivered to a conventional steam turbine for electricity generation or to a storage tank for later use. Efficient movement of the heat transfer fluid appears to limit these plants to around $100 \mathrm{MWe}$ ratings however storage capacity increases their hours of operation and allows them a degree of dispatchability - supplying the market on demand. Technological advances in receivers, power cycles and heat transfer fluids would allow such plants to achieve a higher efficiency in energy conversion.

The levelised cost of electricity (LCOE) is a metric commonly used to compare the relative competitiveness of electricity generating technologies. The LCOE is the price at which a unit of electricity must be generated by a particular plant configuration, to break even over the life of the plant. It is calculated as the sum over the lifetime of the plant of all capital, operations and maintenance costs divided by the cumulative electricity generated by the plant. The units of LCOE (typically for Australia) are dollars per kilowatt-hour ( $\$ / \mathrm{kWh}$ ). Future costs are incorporated through present value calculations and a discount rate.

Key inputs to LCOE are: cost of capital, discount rate, operations and maintenance costs, fuel costs and capacity factor (the proportion of time the plant is generating at its nameplate capacity). Specific regional features such as government financial incentives, the existing generator mix, and geographic attributes influence the LCOE of a particular plant. The details of what is included or not included as input to an LCOE calculation can produce widely different values, making comparison of LCOE estimates from various studies problematic. However, values have been found recently in Australia, using the Longreach solar data; ranging from minimums of !139 and 158/MWh(Hinckleyetal.2011)andfromareund220/MWh (Lovegrove et al. 2012).

Models of a molten salt power tower and a direct steam power tower have been created in SAM, with some input parameters set for Australian conditions. A description of the models is given in Lovegrove et al. 2012 and 2013. A series of these parameters is varied one by one to observe their respective impact on the lcoe of a plant. The relative impacts suggest areas to look for potential improvements in plant design. 


\section{RESULTS}

A broadly accepted figure for the LCOE of utility-sized CSP plants in Australia is $\$ 0.25 / \mathrm{kWh}$. CSP plants are in an early commercial phase and the learning curve will see cost reductions as experience points to best practice in the industry and an increasing number of plants leads to economies of scale. Some cost reductions are likely to be incremental, for example, optimisation in constructing, maintaining and operating heliostat fields, while basic research may develop new materials in heat transfer fluids, receiver construction and heat storage. Sensitivity analysis can be applied to known or assumed costs but not to major technological improvements.

Using model settings as suggested by Lovegrove (2013) and SAM's default molten salt solar tower and its default direct steam using tower, the costs for system components for the two systems were examined (Figures 1 and 2). Energy losses of about $55 \%$ are expected between the collectors and the receiver, some of which are unavoidable (see discussion in Augsburger, 2013). SAM allows for changes in reflectance and soiling and applying a range of values for this variable produced a non-linear decline in LCOE as the variable increased, with perhaps the optimal decrease at around $0.925 \%$ reflectance. There is a similar energy loss from the receiver to electrical output, well discussed in ESTELA 2012. This effect is similar for both plant configurations.

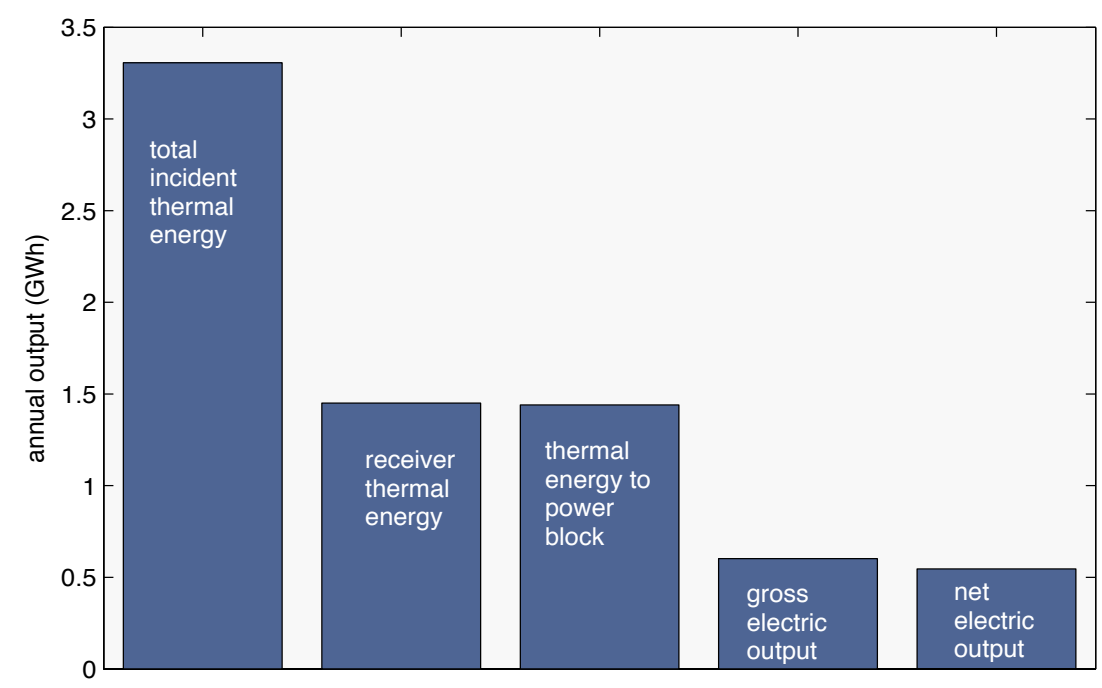

Figure 1. Energy output at various sections of a solar power plant with molten salt storage

For the CSP plant with storage the number of full load hours provided by storage was varied to find an optimal duration for storage (Figure 3). LCOE declines non-linearly as storage time (essentially tank capacity) is added to a minimum around 10 to 11 hours of storage. Figure 3 also shows that the capacity factor of the system (the ratio of annual electricity generation to potential electricity generation) increases with storage capacity then levels off at around the optimum storage capacity. A CSP plant with storage then can achieve approximately twice the capacity factor of the plant using steam directly. This is the effect of storage, allowing a CSP plant to achieve dispatchability whereby the generator can follow the electricity demand curve and sell electricity when demand and prices are highest. It also allows the generator to offer ancillary services to the electricity market, such as network balancing against more variable and intermittent generators.

Figure 5 shows the relative contributions from the various components of the two plant configurations to total cost. The overall cost of the plant with storage is higher $(\$ 885,523,086$ versus $\$ 564,292,698)$ although the LCOE under basic conditions is lower for the plant with storage $(\$ 0.1761 / \mathrm{kWh}$ as against $\$ 0.2231 / \mathrm{kWh})$. Heliostat fields are a major cost to both plants and Figure 6 shows the response of LCOE to variation in the cost of the heliostat field. The decline in LCOE is linear with little difference in the rate of decline in cost 
B. Webby, Sensitivity analysis for concentrating solar power technologies

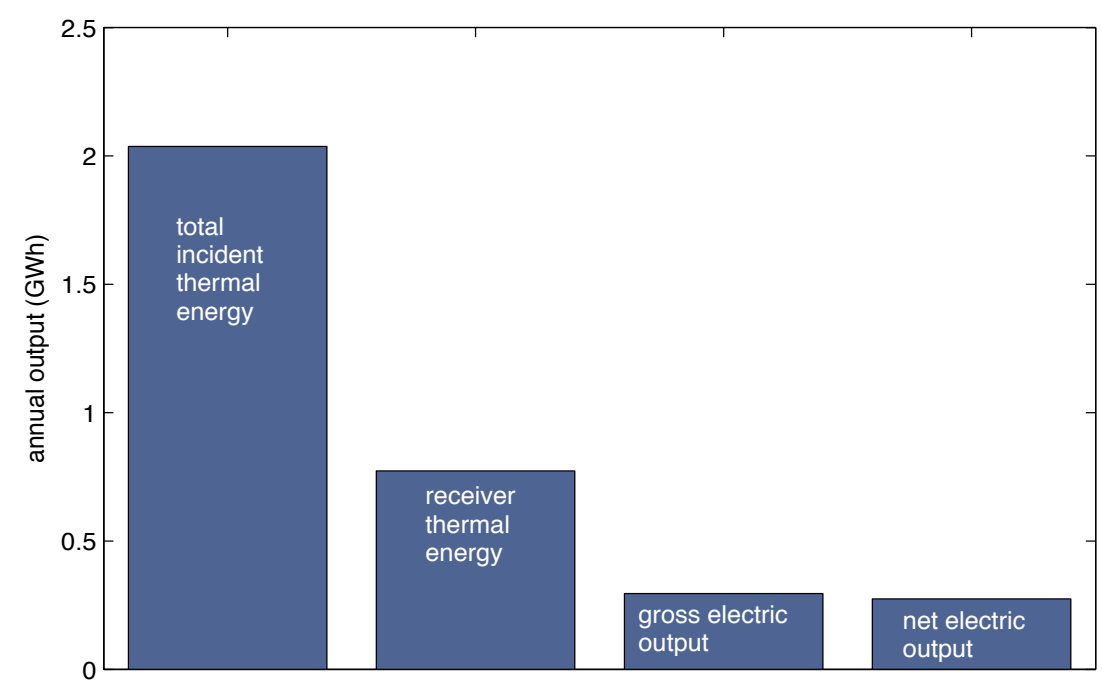

Figure 2. Energy output at various sections of a solar power plant using steam

between the plants.

Varying the cost of storage, and of operation and maintenance costs both produced a linear response in LCOE. The response of LCOE to various sizes of power block suggests there is an economy of scale to be pursued, particularly with the plant without storage.

As a rule of thumb financial costs are more important to the competitiveness of renewable energy generators as they are capital-intensive but have low fuel costs. Thus a low discount rate definition can significantly reduce the LCOE, however one aim of CSP research is to make the technologies commercially competitive with conventional generators and a realistic value for capital must be used in models. Government incentives for renewable-energy powered generators and a carbon price would assist the push but are not considered in this analysis. Likewise, costs of integrating potentially intermittent and variable generator into the national grid and energy market behaviour are not considered. A particular proposal would have local, regional and national matters to include in any model assessing the financial feasibility of such a plant. Many of these factors can be input to SAM.

\section{Conclusion}

Considerable attention is being given to identifying pathways to bring down the cost of generating electricity by CSP plants, in Europe, the US and Australia. This is an early review of potential areas for seeking cost reduction, based on models of CSP plants and a thermo-economic model of their behaviour. Sensitivity analysis showed linear and non-linear declines in LCOE in response to changes in the values of parameters. Variables were tested alone and interactions between variables may be of interest. This analysis could be extended however advice from engineers on the practicality of input values is required.

\section{ACKNOWLEDGEMENT}

The author would like to acknowledge support from the Australian Solar Thermal Research Initiative.

\section{REFERENCES}

Augsburger, G. (2013). Thermo-economic optimisation of large solar tower, power plants (Lausanne: doctoral thesis, 2013).

European Solar Thermal Electricity Association (ESTELA) (2012) Strategic Research Agenda 2020 - 2025 (Brussels: ESTELA, 2012). 
B. Webby, Sensitivity analysis for concentrating solar power technologies

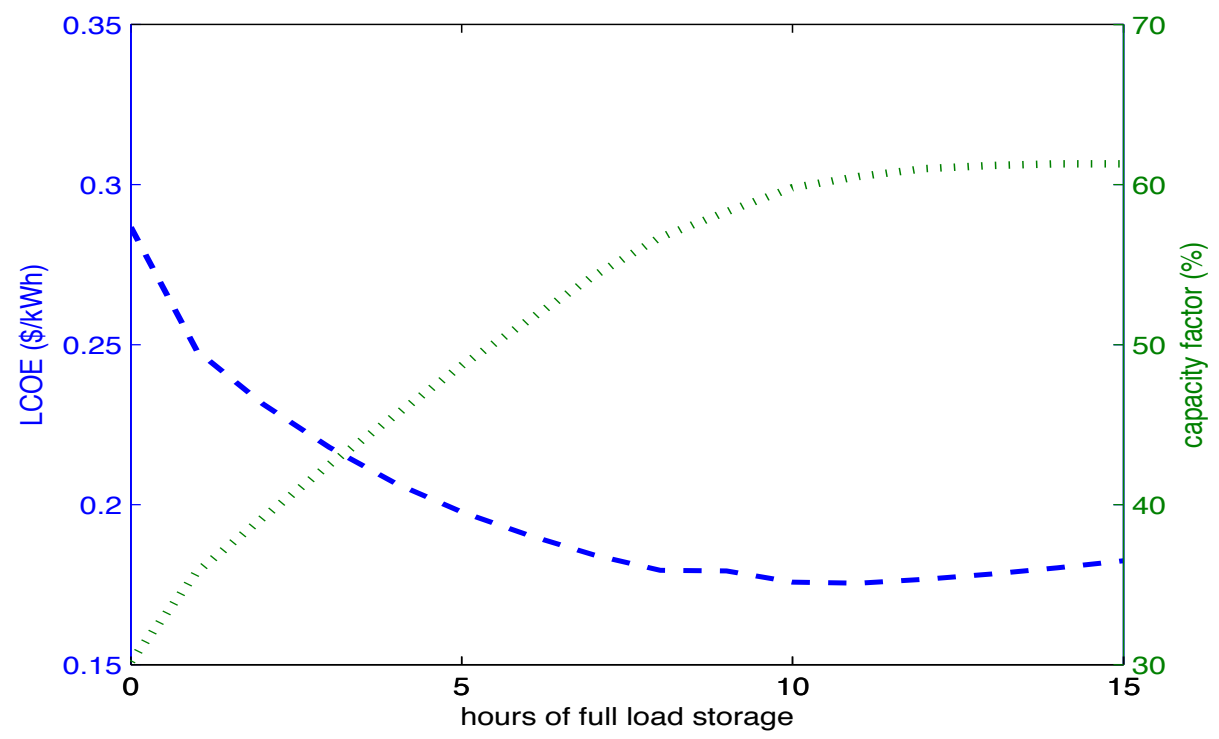

Figure 3. Levelised cost of electricity and capacity factor against hours of full load storage

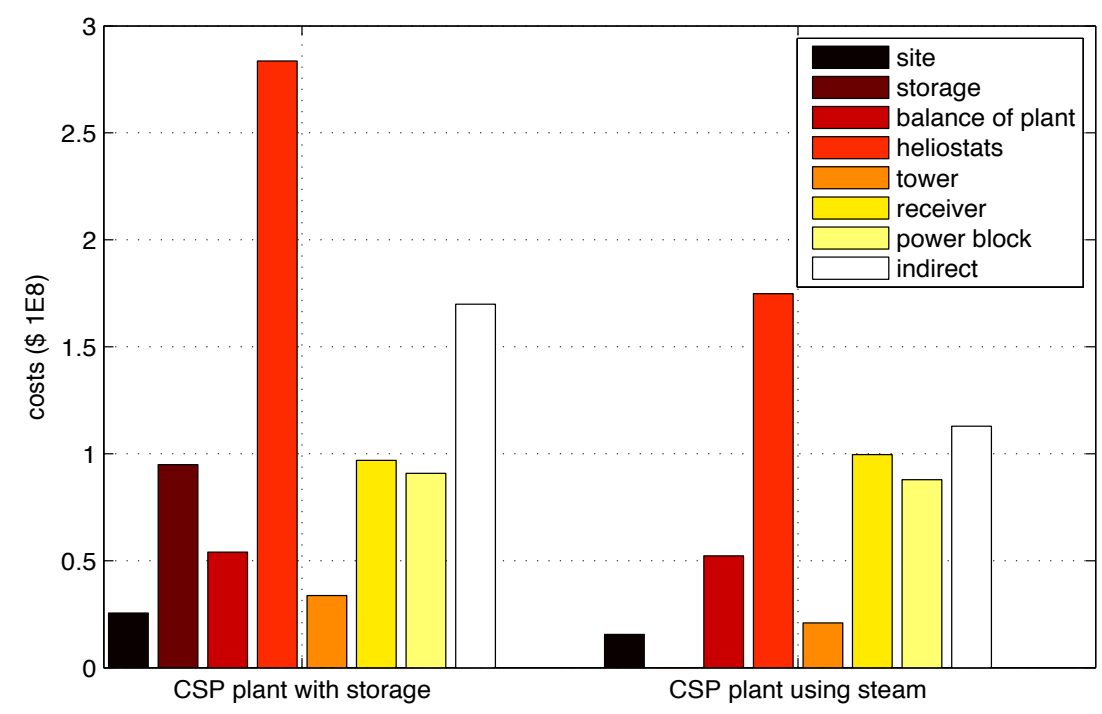

Figure 4. Contributions to total cost of a CSP plant with storage and without

Hinckley, J., B. Curtin, J. Hayward, A. Wonhas, R. Boyd, C, Grima, A. Tadros, R. Hall, K. Naicker and A. Mikhail (2011). Concentrating solar power - drivers and opportunities for cost-competitive electricity (Newcastle: CSIRO, 2011).

Lovegrove, K., S. Franklin and B. Elliston (2013). Australian Companion Guide to SAM for Concentrating Solar Power (Canberra: IT Power, 2013).

Lovegrove, K., M. Watt, R. Passey, G. Pollock, J. Wyder and J. Dowse (2012). Realising the Potential for Concentrating Solar Power in Australia (Canberra: IT Power, 2012). 
B. Webby, Sensitivity analysis for concentrating solar power technologies

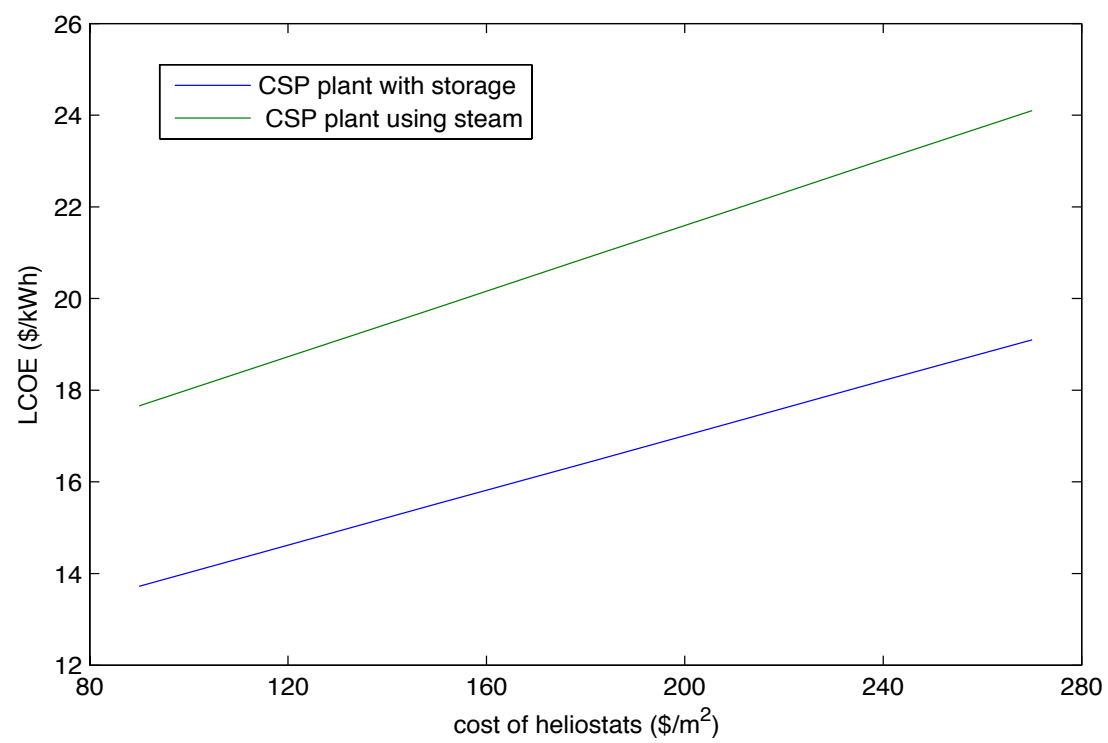

Figure 5. Energy output at various sections of a solar power plant with molten salt storage

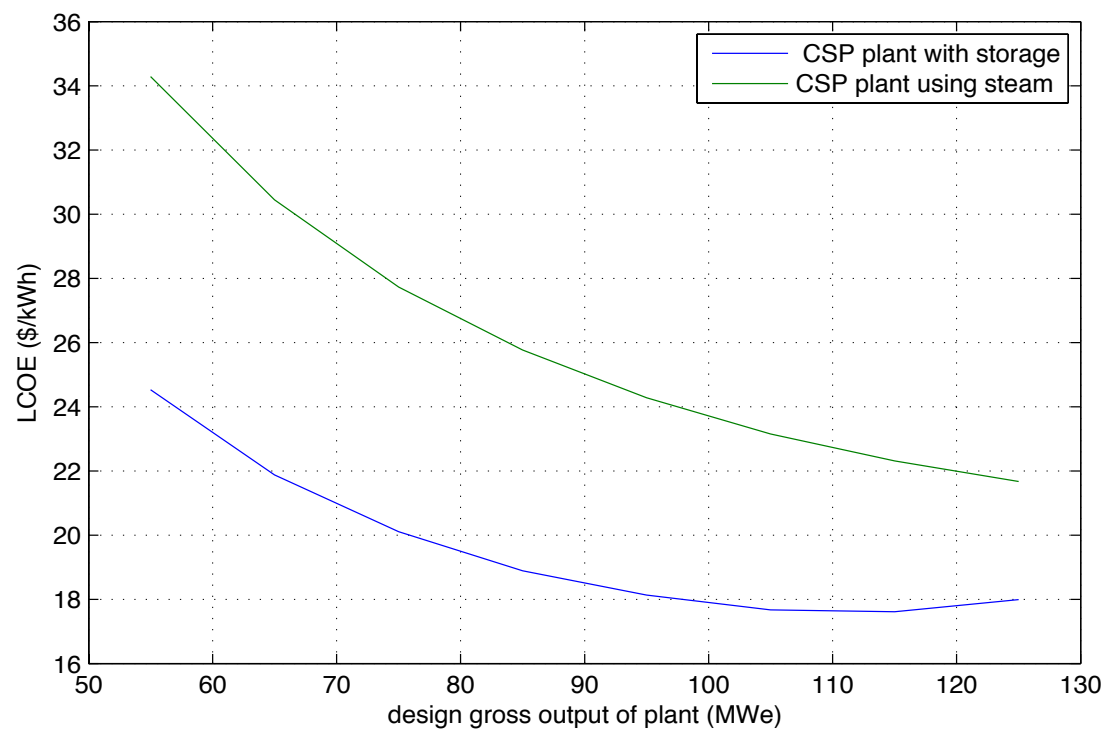

Figure 6. LCOE at various sizes of design gross output of the power block 